\title{
Management and risk in financed projects
}

\author{
Roxana Mironescu, „Vasile Alecsandri” University of Bacau, Romania \\ Nicoleta Ciucescu, „Vasile Alecsandri” University of Bacau, Romania
}

\begin{abstract}
With a caring and professional approach the project management activity may prove to be difficult enough. Many specialists in this field indicates that a project plan can be assimilated to a "roadmap", so, for a clear destination, the shortest path is of most pronounced efficacy in order to achieve that purpose, to travel the distance between a current state and desired state and all this is established and configured before we hit the road, all risks included, expected or not. In this paper we present a draft European-style management, which intends to conduct a communion of all the decision makers involved in creating a healthier community.
\end{abstract}

\section{Keywords}

Healthy community, project, Project Management, risk, roadmap.

\section{JEL Codes: M 20, 012}

The project may be viewed as a sequence of activities that produce measurable results. That sequence is created, designed in its final phase, starting from the way the funding source defines the final outcome. A design approach involves taking some risks which will run in its way during this project.

Traditionally, risk is defined by negative aspects entailed, by its ability to negatively influence the development of an organization, an activity, to achieve goals. Risk, perceived as a loss in the funded projects, can take forms such as costs to achieve the goals or to finish the products are higher than those that were originally planned, the results / final products are of inferior quality or lower than originally projected; resources used in the project have been exhausted or even irrationally used; targets or deadlines for delivery of results to beneficiaries have been overcome, and the most serious risk is the total failure of the project. Risk can arise either due to the action of intrinsic or extrinsic disturbing factors, in the project, but we must keep in mind that every project includes a degree of risk, because we can not predict the future with utmost certainty. The risk may increase as the project lasts longer, as the time interval between phase of planning and its implementation phase is wider. Also, the project manager's experience, the team working's experience and, generally speaking, the experience of the organization can negatively influence, if they are limited, the whole quality project results. To these, we can add the project risks generated by the use of methodologies and technologies so new, less verified and hazardous. In a more artistic speech, risk management is a process that proved its similarity to a medical examination, which, after treatment the doctor ordered, after the disease diagnosis, the patient is far away from healing, but he returns to the doctor and he is worse than before treatment.

One can appreciate that risk management in projects financed are carried out in three stages: a) setting (description) risk - the risk of problems in charge of the project to translate information about the objectives and organizational resources on a so-called "map" of risk permanently updated and adapted to changes in the real environment. Answers to questions such as: "what can happen?", "Which causes the production of a specific type of event?", 
"May manifest as a disruptive event?" Activities covered by that stage. Efforts to identify potential risks involves taking the following steps: study of problems encountered during the course of similar projects, request the opinion of as many professionals concerned by the project more precise formulation of the potential risks and, where possible, eliminating a substantial amount of them; b) measures for combating the risks involved - the person who is responsible for such problems in the project need to master the tools by which risk is avoided or transferred to other areas, in order to reduce the impact. When producing negative effects of a particular type of risk can not be avoided, as such should be responsible to control the impact, to develop and implement risk management plan, when it turns from potential effectively; c) control and monitoring results - development of risk and potential risk situations is continually monitored, and based on the permanent risk management plan is corrected and updated.

Project risk management is a circular process which runs continuously. As for business management as a whole, the ability to record your feedback, understand the signals recorded as the initial conceptual plan ensures a flexible approach, marked by dynamism. The project is more likely to achieve success in the real environment, that is, by force of things, unpredictable and uncertain as the project you describe.

Turin lead an URBACT thematic network on the theme "Building Healthy Communities" Building Healthy Communities (BHC) - Urbs Health Network for "Building Healthy Communities."

The main objective of the project is to create a network of cities of at least 6 different countries to participate in transnational exchange program in which transfer policies, plans, drawings and practices on urban health policy, in order to increase capabilities and knowledge for professional development in urban health.

The main problems are emerging on selected The project will focus on the following specific sub-themes:

- health impact assessment and urban Health Indicators: Health Impact Assessment (Health Impact Assessment - HIA) is regarded as a major opportunity to integrate health in all policies. HIA promises to influence decision-making process, specifying all factors determinative of health, attacking all the injustices and providing an impetus for participation and empowerment in health. Thus, the HIA provides methodology that makes possible health problems to be included in integrated urban development plans.

- In 2005, the work plan of the EU Public Health Programme has identified the development of an urban health indicator system is essential to the understanding of health information and the system itself.

- Active Ageing: Research shows that if people remain healthy as long as life, hospitalization number of elderly people will be halved. Healthy aging can be supported by activities that promote health and prevent disease throughout the life by addressing key issues such as unhealthy nutrition, physical activity, alcohol, drugs and tobacco, risks of environmental, road accidents and the household.

- Use of Structural development "Health revenues. Health problem is one of the priorities identified in the "urban dimension" of cohesion policy. Several Member States have already used the structural and cohesion funds in order to solve some health problems, one for the network being to focus on exchange of experience to use Structural instruments for health problems. Sound locations and healthy average: Analyzing the interaction between environment and health, we study how health is affected not only by pathological factors but also factors in physical and social environment.

The project includes 2 two phases: Phase 1, which consists in forming a partnership of 10 cities with their appropriate management authorities, undertake a study of problems, needs and actions for health. They also established 10 Local Support Groups (GSL). In Phase 2, it is provided an exchange among 100 key players (10 members from each city partner GSL) and the formation of 10 Local Action Plans related to funding sources at European, national 
and local level and shape some courses of action with instructions to future health interventions.

Local support groups on the URBACT II (GSL / ULSG) were created to increase the impact of the URBACT II Programme. All thematic networks and groups that are part of the URBACT II are required to establish a local support group in the development phase to proceed to implementation phase of the project.

However, USLG sites should not be perceived as a simple administrative request to be part of the program. Main purpose of local support groups is to disseminate knowledge of transnational exchanges by a wide range of local co-participants and to oversee that this will change locally. In addition, the large number of local coparticipanților ULSG involved are able to engage in community URBACT, which may take some messages about the central cities to pass.

The major objective of all GSL / ULSG is to improve the impact of exchange at the local level. The specific objectives of a specific GSL / ULSG and activities and composition, must be adapted to ensure that the overall goal is achieved. There is no magic formula - depends on the nature of the exchange proposed project, nature of local needs and experience in the City / partner. Creating GSL depends on what already exists in the city and in the case there are several created possibilities and there depends to the disponibility to go on.

After settings, GSL can begin the basic studies in an interactive and dynamic way by using the following:

-Testing some specific issues with stakeholders;

- Perfecting or reformulating various topics;

- Obtaining references and other co-participants and so on.

How far GSL reach the stage of development depends on the point of departure and subject to the deadline of the city. Specific objectives to be met from the start:

1. Clarification of special needs or concerns of the city, compared with Thematic Network or Working Group;

Identification (mobilization and validation) of what has really given the project the city as best practices, existing instruments, visiting different locations, policies and other experiences;

Ensuring that this knowledge is reflected in basic research during the development phase (phase 1) and the Local Action Plan will be prepared during implementation phase;

Dissemination of project results in a much wider local audience;

The activity as the main supporters of the project. GSL involvement occurs in two ways:

Development phase

- 1 - the primary and key stakeholders should provide information on:

- Identify the specific needs of the City of subthemes addressed by the project;

- Experience subthemes addressed by the project;

- advice on basic research;

- advice on software developed by the project, especially regarding the operation of the GSL and its relationship to the project concerned; and implementation stage

- 2 - Role of Local Support Group - GSL in the second phase consists of:

- Participation in the design and monitoring of local action plan;

- Identify and validate inputs, such as case studies;

- Participation in the various exchanges and presentation by co-participants;

- Regular meetings, particularly with regard to training seminars for project partner contribution;

- Comments on final results;

- Testing of certain recommendations;

- Participation in local web platforms;

- Setting the local supporter of the project and conducting lobbying for specific changes;

- Local Organizing dissemination events;

- media awareness campaign to attract local and its project activities. 
To achieve the overall objective and specific objectives for 2007-2013, envisaged steps and actions are grouped in six national development priorities:

- Increasing economic competitiveness and development of knowledge-based economy;

- Developing and upgrading transport infrastructure; - Protect and improve environmental quality;

- Human resource development, promoting employment and social inclusion and strengthening administrative capacity;

Developing the rural economy and increasing productivity in agriculture; Reducing development disparities between regions of the country. Environmental objective, accordingly to the NDP:

Table no 1. the main environmental objectives of the analyzed project

\begin{tabular}{|c|c|}
\hline $\begin{array}{c}\text { Shortcomings in environmental services } \\
\text { and facilities throughout the country and } \\
\text { particularly in rural areas. }\end{array}$ & $\begin{array}{c}\text { Water and soil } \\
\text { Air and climate changes ( and natural } \\
\text { resources) }\end{array}$ \\
\hline $\begin{array}{l}\text { Conserving the biodiversity and the } \\
\text { uniques natural areas in Romania }\end{array}$ & $\begin{array}{c}\text { Biodiversitate Biodiversity } \\
\text { Air and climate changes ( and natural } \\
\text { resources) }\end{array}$ \\
\hline $\begin{array}{l}\text { Growing importance of sustainable } \\
\text { development and advancing the list of } \\
\text { commercial, political and social priorities. }\end{array}$ & $\begin{array}{c}\text { Cultural heritage and natural landscapes. } \\
\text { Quality of life } \\
\text { Air and climate changes ( and natural } \\
\text { resources) }\end{array}$ \\
\hline
\end{tabular}

The North - Eastern Regional Strategy - 2007-2013, Bacau being a part, has the priority "Infrastructure and Environment" measure following: rehabilitation and development of educational, social and health. The objectives of this measure are:

-Improvement of training;

-Increasing population health in the region;

-Supporting the social inclusion of marginalized and socially excluded groups through rehabilitation and upgrading of related infrastructure in such services.

In addition to objectives set by the National Development Plan this project proposes: - Implement a pilot project in Bacau on quality of life assessment based on a set of indicators with a composition similar to that in EU countries (and considering new legislation in Romania);

- Monitoring of environmental factors, social, economic and cultural factors that can affect health and quality of life in Bacau, by reference to the indicators mentioned above; - Creating a local action plan which primarily aim to improve quality of life for the people of Bacau. It would involve government organizations and local community for development and implementation of Local Action Plan.

Specialists in risk management support the idea that complete elimination of risk is an utopia or may be an option with low efficiency, in terms of cost. Therefore, efforts should be directed to monitor it and if a threshold of risk, both in terms of likelihood and impact. Risk management does not remove it entirely, but it is an indispensable process in the project. Moreover, risk analysis should precede the onset of the project and if this analysis is drastically negative result, which shows that the risk is unacceptable, the project may be abandoned entirely, since the design phase.

Contemporary analysis shows that dedicated risk management, unlike traditional approaches that focus primarily on actions to counter, focuses on modern methods for anticipating action, simulation and prediction of risk. Current methods conceptual transferred from reaction, counteraction, the action, defense. Furthermore, the analysis revealed the beneficial aspect of risk that is not an entirely negative phenomenon, comprising both positive and 


\section{Studies and Scientific Researches - Economic Edition, no. 15, 2010}

negative, differentiated proportions. Risk is a concept that refers not necessarily, the potential negative impact events as the consequences of uncertainty and change which may arise from the initial planning. Roger Van Scoy, in his work entitled "software Development Risk: Opportunity, Not Problem", Software Reviews Ingineering Institute, USA, 1992, underlined "the risk is not a bad thing in itself, risk plays an essential role for progress, and failure is often part of learning." It is important to maintain a balance between risk and potentially negative consequences of possible benefits that may result in the transformation of risk into opportunities.

Understanding of project risk as "opportunity" prompt recovery of the unexpected has become a dominant style of management in large companies in the contemporary period. Risk management approach is not limited, rigid, guided solely by the objective of containment or control any potentially adverse effects of various events, but it is a method to increase flexibility and adaptability of firms in an more complex environment and hence more uncertain.

\section{References}

1. Van Scoy, R. (1992), Sofware Development Risk: Opportunity, Not Problem, Software Ingineering Institute Review, USA;

2. Luisot, J.P. ( June 2003), What Makes an Effective Risk Manager?, Risk Management Magazine, USA;

3. ${ }^{* * *}$ www.projectmanagement.ro. 